\title{
Serviço social e movimentos sociais - uma não-relação?
}

Leonie Wagner ${ }^{1}$

Serviço social e movimentos sociais na Alemanha historicamente parecem estar intimamente relacionados (cf. Müller, 1997; 1999; StaubBernasconi, 1995). O movimento de mulheres, por exemplo, contribuiu decisivamente no final do século XIX e início do XX para o estabelecimento da formação profissional e para a profissionalização do Serviço Social; o movimento de jovens fez um trabalho pioneiro, sob a perspectiva sóciopedagógica, depois da I Guerra Mundial; e o movimento operário contribuiu pelo menos indiretamente para a criação de um sistema diferenciado de política social. Também os novos movimentos sociais deram impulsos importantes para o Serviço Social: seja na assitência à juventude através da escandalização das circunstâncias nas instituições educacionais, no trabalho com mulheres através da tematização das situações de violência, ou na psi-

\footnotetext{
${ }^{1}$ Doutora em Pedagogia Social pela Universidade de Kassel, leciona na Fachhochschule Erfurt; participou do projeto de pesquisa Probral Movimentos sociais e a luta pelos direitos de cidadania. Endereço: leoniewagner@ netdirekt.de. Publicado originalmente em SozialExtra, Opladen, $n^{\circ}$ 8-9, 2003 e reproduzido com autorização. Tradução do alemão: Emil A. Sobottka.
}

Civitas, Porto Alegre, v. 4, nº 1, jan.-jun. 2004 
quiatria através do questionamento de concepções de normalidade.

Esta vinculação estreita também parece óbvia porque os movimentos sociais tematizam problemas e contradições que parecem não ser passíveis de solução, ou de solução satisfatória, mediante as formas tradicionais de organização social. Em boa medida, estes são também os problemas com os quais o Serviço Social se ocupa ou aos quais ele deve(ria) reagir. Movimentos sociais são tanto expressão como motor da transtormação social; isto é, eles apontam para mudanças necessárias e participam do processo de sua efetivação. O Serviço Social também reage à transformação social e tem como tarefa ocupar-se de deficiências velhas e novas na realidade social.

Depois de um auge dos movimentos sociais nos anos 70 e 80 do século $\mathrm{XX}$, havia um certo silêncio em torno dos movimentos sociais na Alemanha. Somente nos últimos anos parece voltar a haver movimento na seara dos movimentos sociais: crítica à globalização ${ }^{2}$ tornou-se o foco novo e internacional de diferentes formações de movimentos. Sintetizando-o de forma um pouco grosseira, o que está em questão são as exclusões sociais geradas por um desenvolvimento e uma política econômica nacional e internacional orientada por uma lógica de mercado aparentemente autocêntrica. A crítica à globalização volta-se contra uma lógica liberal que reforça as contradições sociais na medida em que, por exemplo, benefícios financiados ou subvencionados pelo estado são (ou deveriam ser) transformados em ofertas de serviço na forma de mercadoria no mercado. Efeitos desta política revelam-se por exemplo no sistema de saúde, onde cada vez mais riscos que outrora eram assegurados através do princípio da solidariedade agora são retirados do catálogo de benefícios legalmente assegurados. A crítica à globalização com isso também volta-se contra um modelo segundo o qual os indivíduos, seguindo um comportamento econômico-racional ou de "empreendedor", devem proteger-se particularmente contra determinados riscos (cf. Lessenich, 2003). Um possível fracasso não é considerado como um defeito do sistema, mas como um fracasso individual. Contra este tipo de desenvolvimento os movimentos sociais críticos da globalização propõem idéias como justiça social e solidariedade, e tentam desenvolver alternativas concretas (como a taxa Tobin).

O serviço social tem a ver com estes desenvolvimentos em diversos

\footnotetext{
${ }^{2}$ Por razões de espaço não posso aprofundar neste texto algumas diferenciações em conceitos relevantes. Isso vale principalmente com relação aos movimentos sociais e à inclusão, nesta categoria, dos movimentos conservadores, de direita. Também o conceito de globalização será aqui apenas esboçado.
} 
níveis: por um lado, a pressão pela privatização tem efeitos sobre os campos de sua atuação. O problema neste caso não é tanto o aumento do número de assistentes sociais que se tornaram autônomos, mas a crescente divisão em uma espécie de assistência social de duas classes: ofertas padronizadas para todos e medidas especiais adicionais apenas para aqueles que podem pagálas. Além do mais, com isto o mandato social do serviço social recebe uma ênfase unilateral: superação de deficiências individuais com o objetivo de promover a adaptação ou inserção no mercado (de trabalho). Ao mesmo tempo é possível prever que uma reforma radical do estado de bem-estar social com a simultânea eliminação do princípio da solidariedade abrirá um amplo campo de trabalho para o serviço social - infelizmente sem uma base suficiente de financiamento público.

Face a esta situação, seria de se esperar uma relação estreita entre os movimentos sociais críticos da globalização e o serviço social. Surpreendentemente, contudo, uma cooperação até agora não está ocorrendo. É bem verdade que se encontram nos movimentos uma série de pessoas oriundas de profissões sociais, mas uma interconexão crítica ou de apoio recíproco das respectivas preocupações ainda está por acontecer.

No presente texto eu quero advogar em favor de uma ligação necessária entre serviço social e movimentos sociais, e reconstruir a fundamentação para esta tese a partir dos laços históricos de ligação entre estes dois projetos. Inicialmente quero apontar para o fato que historicamente esta relação de forma alguma era óbvia, para então listar os motivos para uma aproximação. Então será possível derivar algumas indicações para a necessidade de uma cooperação tanto para o serviço social como para os movimentos sociais.

\section{Uma relação óbvia?}

Alice Salomon ${ }^{3}$ descreveu num texto de 1912 a relação entre o serviço social e o movimento de mulheres e, em divergência à imagem tradicional, ela constatou que não se trataria , de forma alguma, de uma relação óbvia. ${ }^{4}$ Ao contrário, o movimento de mulheres e o serviço social nos seus inícios teriam delimitado de forma estrita a área de atuação um em relação ao outro. No caso do serviço social, esta postura pode ser fundamentada com a convocatória para a fundação dos grupos de moças e mulheres para o

\footnotetext{
${ }^{3}$ Alice Salomon (1872-1948) foi uma representante destacada do movimento burguês de mulheres e uma das principais fundadoras do serviço social profissional na Alemanha.

${ }^{4}$ Tentativas posteriores de determinar a relação entre o serviço social e os movimentos sociais se ocupam menos com as diferenças iniciais ou tentam fundamentar a imediata ligação entre eles (cf. p. ex. Mennicke, 1931-32; Treuge, 1931-32).
} 
serviço social de ajuda, na qual foi explicitamente fixado que não deveria tratar-se de "nenhum tipo de aspirações emancipatórias". Face à legislação relativa às associações civis na Alemanha, que proibia às mulheres a participação em quaisquer atividades que pudessem ser consideradas, ainda que tenuemente, "políticas", esta postura inicial era perfeitamente compreensível. Mas o que impediu o movimento de mulheres a se aproximar do serviço social? Resumidamente Salomon constata neste caso que para o movimento de mulheres só ficou claro depois de um bom tempo que ao lado da exigência de direitos também era necessário assumir responsabilidade social, e que as reformas desejadas ou conquistadas também deveriam ser transportadas para dentro da sociedade (Salomon, 1912, p. 117-18).

Com relação ao movimento de juventude também não se revela nenhuma relação óbvia com o serviço social. Somente depois da Primeira Guerra Mundial o serviço social foi desbravado como um campo de atuação que fosse além da "auto-ajuda". E este desenvolvimento não encontrou um apoio unânime nas ligas juvenis, senão que ocasionalmente foi confrontado com a suspeita da introdução de "tendências estranhas à natureza" do movimento (Buchhierl, 1974, 1478).

A relação dos novos movimentos sociais para com o serviço social estava constituída de forma semelhante: também neste caso havia inicialmente reservas maciças de parte dos movimentos para com o serviço social. Aqui mencionarei apenas dois exemplos brevemente:

(a) A direção nacional da Liga Estudantil Socialista Alemã (Sozialistischer Deutscher Studentenbund, SDS) declarou em 1969 que não pretendia apoiar financeiramente ações realizadas no marco da "estratégia para os grupos marginalizados" (p. ex. campanhas de domicílios), porque tais atividades "com o lumpenproletariado [...] não seriam uma estratégia revolucionário-promissora" (Schrapper, 1990, p. 420).

(b) O novo movimento de mulheres inicialmente também tinha uma relação em parte bem distanciada para com o serviço social. A tematização das áreas declaradas como privadas (gravidez, educação dos filhos etc.) foi declarada como apolítica e rejeitada.

Por conseguinte, a concepção acerca daquilo que seja político ou privado parece ter um papel considerável para a relação entre o serviço social e os movimentos sociais. Pelo menos no seu início os movimentos sociais tendem a rejeitar a idéia de ocupar-se com "as coisas privadas", e aspiram transformações -sociais ou políticas- mais abrangentes. Neste momento o serviço social parece apolítico e inadequado, quando não um estorvo para os objetivos do movimento. O movimento operário é um 
paradigma para esta postura, pois por longo tempo rejeitou o serviço social e as reformas sociais porquanto julgava que uma melhoria da situação de classe poderia enfraquecer as forças revolucionárias que ele queria mobilizar (p. ex. Ritter, 1998). Somente os desenvolvimentos posteriores do movimento levam a que ele volte seu olhar mais fortemente para a importância que a esfera privada pode ter para as mudanças sociais, e relações mais estreitas com o serviço social podem ser então construídas.

Lá onde o serviço social e os movimentos sociais então se aproximaram, isto freqüentemente ocorreu através de uma perspectiva crítica: crítica comum às situações sociais, políticas ou econômicas, que tornam necessário tanto o serviço social como os movimentos sociais. Mas crítica também às formas atuais da assitência ao bem-estar ou do serviço social (StaubBernasconi, 1995, p. 58 et seq.).

\section{Uma relação crítica?}

Quais eram os pontos críticos centrais a partir dos quais as relações entre serviço social e movimetnos sociais foram constituídas?

De parte do antigo movimento de mulheres, a crítica estava voltada sobretudo à deficiente profissionalização dos serviço social: era contra uma "ajuda" sem planejamento, que era prestada antes a partir de um sentimento caritativo do que por responsabilidade social. A isto foi contraposta uma formação (acadêmica) na qual deveriam ser proporcionadas as bases para uma atividade baseada em conhecimentos modernos. Ao mesmo tempo era manifestada com isso uma crítica a um sistema social e político que não apenas permite injustiças e discriminações, mas em parte inclusive as gera através de normas e decretos. Neste sistema o serviço social deveria intervir em conjunto com o movimento de mulheres e influenciar tanto indireta como diretamente na reforma da realidade social.

O movimento da juventude analisou detalhada e criticamente sobretudo as condições na educação tutelar, e tentou mudá-las. As conseqüências negativas do trancamento e da estigmatização de jovens por meio da educação tutelar foram desveladas, e novos conceitos de reforma pedagógica foram desenvolvidos. Tratava-se sobretudo da crítica ao trato da juventude, que tinha muito pouco a ver com os ideais democráticos. Nos anos sessenta do século XX o movimento estudantil reagiu a circunstâncias e problemas similares na educação por internamento. Nas duas oportunidades o serviço social, como instrumento da sociedade, era objeto da crítica, porque ele se engajara não no sentido da clientela, mas unilateralmente no sentido de um desenrolar tão pacífico quanto possível da guarda destes jovens, ou até mesmo praticava métodos e objetivos 
educacionais reacionários. De um modo geral, o serviço social foi criticado pelos novos movimentos sociais justamente ali onde ele não tomou conhecimento das causas sociais da marginalização e descriminação e, ao invés disso, desenvolvia um trabalho voltado unicamente para a mudança e adaptação dos indivíduos (Staub-Bernasconi, 1995, p. 58 et seq.).

No contexto destas relações críticas foram então concebidas e implementadas iniciativas inovadoras. Com isso os objetivos dos movimentos sociais foram traduzidos em prática social e aplicados. Isso significa que a partir da crítica foram desenvolvidas alternativas, e assim ampliaram-se os campos de atuação e os métodos do serviço social.

Com relação a estas alternativas, contudo, iniciou-se nos anos oitenta e crescentemente nos anos noventa do século XX um processo que teve como conseqüência uma crescente profissionalização e institucionalização. Também é possível constatar um desenvolvimento paralelo para os movimentos sociais: com o reconhecimento social (parcial) dos movimentos sociais, temas centrais passaram não apenas a serem tratados isoladamente, mas o próprio tratamento das questões foi crescentemente delegado a organizações dos movimentos ou a organizações não-governamentais. Estes processos, conjugados com um interesse decrescente em questões sociais e políticas, levaram a uma "normalização" tanto do serviço social como dos movimentos sociais.

Estas transformações foram acompanhadas de uma despolitização dos problemas sociais, uma re-individualização que encontra sua expressão refinada nos projetos de política e de sujeito neoliberais.

\section{Uma relação necessária?}

A partir dos desenvolvimentos históricos é possível formular duas teses relativas à atual não-relação entre serviço social e movimentos sociais na Alemanha:

1. os movimentos críticos da globalização (ainda) não reconheceram a importância do serviço social no processo da mudança social e vêem o serviço social enquanto campo de trabalho como sendo "apolítico", sem derivar daí uma crítica;

2. o serviço social (ainda) não reconheceu a importância da mudança social, para a qual os movimentos sociais podem ser vistos como (um) indicador, ou ele atualmente não necessita uma apreciação crítica de seus métodos, conceitos ou teorias.

Com relação à primeira tese, haveria então que observar, no mínimo, 
que os movimentos sociais desconsideram uma possibilidade importante de alianças. Isto é tanto mais surpreendente na medida em que um dos teóricos dos movimentos sociais críticos da globalização, Pierre Bourdieu, em suas reflexões a respeito da constituição e implementação de um modelo "alternativo", apontou para a necessidade que os novos movimentos sociais emergentes têm, de formular alternativas concretas que sejam realizáveis na prática. Nessa reflexão, ele se refere a moradia, trabalho, saúde e a questões relativas aos estrangeiros, e atribui uma importância decisiva à solidariedade e à inclusão daqueles que são atingidos negativamente pelas consequiências da globalização (Bourdieu, 2001). Por conseguinte, uma aliança pareceria óbvia, pois na formulação da crítica concreta aos efeitos negativos de processos de globalização, o serviço social pode apoiar-se num amplo espectro de conhecimento. Também no que diz respeito à elaboração de alternativas concretas realizáveis ele tem experiências que poderiam ser recuperadas e ampliadas.

No entanto, para alianças necessita-se sempre de pelo menos duas partes, e assim pode-se admitir que também no serviço social não se possa detectar aspirações para o estabelecimento de um relacionamento com os movimentos críticos da globalização. Uma explicação possível para esse desconhecimento poderia ser que as consequiências das mudanças neoliberais não são percebidas suficientemente. Nas discussões teóricas e na formação, esta perspectiva parece estar claramente presente. Mas é surpreendente que isto aparentemente não se manifeste no nível da prática.

Em minha opinião esta discrepância aponta para a questão da autocompreensão do serviço social como profissão na Alemanha. As discussões dos últimos anos em torno do estabelecimento de uma tal autocompreensão em alguns segmentos caracterizam-se sobretudo pela queixa a respeito de sua ausência. Ao mesmo tempo é percebida por muitos lados uma necessidade de se emancipar da heteronomia e com isso conquistar o poder de definição acerca daquilo que o serviço social é e deve ser.

Se este desafio for assumido positivamente face aos processos de globalização, então, em minha perspectiva, resulta a necessidade de uma autocopreensão na qual ao lado do trabalho com a clientela também deveriam ser tematizadas novamente as interdependências com processos sociais, políticos e econômicos. Isso envolve uma pretensão no sentido de uma "crítica engajada da sociedade capitalista do bem-estar no tocante àqueles pontos onde injustiça social é produzida e glorificada" (Thole, 2000, p. 240). E, além disso, requer também uma reflexão e processamento da contribuição própria para o surgimento e a manutenção de tais realidades. Também aqui em princípio já se dispõe de concepções; neste 
aspecto, a definição da Federação Internacional de Serviço Social (2000) a respeito do serviço social parece-me particularmente apropriada, pois nela se aponta para a importância da profissão para o fomento à mudança social: "The social work profession promotes social change, problem solving in human relationships and the empowerment and liberation of people to enhance well-being."

Uma compreensão assim da profissão contém, além disto, também o reconhecimento da necessidade de alianças às quais caberia, ao lado de uma função de apoio recíproco, também a tarefa da reflexão (auto)crítica. Neste sentido, o serviço social na Alemanha não deveria esperar até que os movimentos sociais se voltem a ele -e o critiquem-, mas deveria ele próprio também movimentar-se.

\section{Referências}

ALTVATER, Elmar; MAHNKOPF, Birgit. Grenzen der Globalisierung: Ökonomie, Ökologie und Politik in der Weltgesellschaft. $5^{\text {a }}$ ed. Münster: Westfälisches Dampfboot. 2002.

BOURDIEU, Pierre. Gegenfeuer 2: Für eine europäische soziale Bewegung. Konstanz: UVK Verlagsgesellschaft, 2001.

BUCHHIERL, Gustav. Jugendbewegung und Soziale Arbeit. In: KINDT, Werner (Org.). Die deutsche Jugendbewegung 1920 bis 1933: Die bündische Zeit. Quellenschriften. Düsseldorf/Köln: Diederichs, 1974, p.1477-1483.

BURO, Andreas. Das Jahrhundert der sozialen Bewegungen. Forschungsjournal Neue Soziale Bewegungen, Stuttgart, v. 13, n. 1, 2000, p. 5-16.

Forschungsjournal Neue Soziale Bewegungen. v.1/2002: Transnationale Aktionsnetzwerke. Chancen für eine neue Protestkultur? Stuttgart: Lucius \& Lucius.

IFSW - International Federation of Social Workers. Definition of Social Work. 2000. (http://www.ifsw.org/Publications/4.6e.pub.html).

LESSENICH, Stephan. Im Dienste des großen Ganzen: Die Ich-AG als Chiffre eines Umbruchs. In: Freitag: Die Ost-West-Wochenzeitung. Berlin: Zeitungsverlag "Freitag", 7.2.2003, p.7.

MENNICKE, Carl. Die Jugendbewegung als Impuls der Wohlfahrtspflege. In: Die Frau, Berlin, v. 39, 1931/32, p. 396-398.

MÜLLER, Wolfgang C. Wie Helfen zum Beruf wurde: Eine Methodengeschichte der Sozialarbeit. v. 1: 1883-1945. Weinheim/Basel: Beltz, 1999; v. 2: 1945-1995. $3^{\text {a }}$ ed. Weinheim/Basel: Beltz, 1997.

RITTER, Gerhard A. Soziale Ideen im 19. Jahrhundert. In: Id. Soziale Frage und Sozialpolitik in Deutschland seit Beginn des 19. Jahrhunderts. Opladen: Leske \& Budrich 1998, p. 9-25. 
SALOMON, Alice. Frauenbewegung und soziale Arbeit. In: Id. Was wir uns und anderen schuldig sind: Ansprachen und Aufsätze für junge Mädchen. Leipzig/Berlin: Teubner, 1912, p.117-127.

SCHRAPPER, Christian. Voraussetzungen, Verlauf und Wirkungen der "Heimkampagnen". Neue Praxis, v. 5, 1990, p. 417-428.

STAUB-BERNASCONI, Silvia. Das fachliche Selbstverständnis Sozialer Arbeit Wege aus der Bescheidenheit. Soziale Arbeit als "Human Rights Profession". In: WENDT, Wolf Rainer (Org.). Soziale Arbeit im Wandel ihres Selbstverständnisses. Freiburg: Lambertus 1995, p. 57-80.

Die WTO als Managementaufgabe oder die Globalisierung der Sozialen Arbeit. Socialmanagement. Zeitschrift für Sozialwirtschaft. Baden-Baden, n. 1-2, 2000.

THOLE, Werner: "Sozialarbeitswissenschaft" - ein Zukunftsprojekt (?). In: PFAFFENBERGER et.al. (Org.): Von der Wissenschaft des Sozialwesens. Rostock: Neuer Hochschul-Schriften-Verlag, 2000, p. 240.

TREUGE, Margarete. Die Frauenbewegung als Impuls der Wohlfahrtspflege. Die Frau, Berlin, v. 39, 1931/32, p. 392-395. 